\title{
EXPERIMENTAL CHARACTERIZATION OF DEGRADATION OF REACTIVE RESIN FILLED WITH ORGANIC MICROPARTICLES
}

\author{
Karolina Habrova ${ }^{1}$, Petr Valasek ${ }^{1}$, Roberto D'Amato ${ }^{2}$, Anna Rudawska ${ }^{3}$ \\ ${ }^{1}$ Czech University of Life Sciences Prague; ${ }^{2}$ Universidad Politecnica de Madrid, Spain; \\ ${ }^{3}$ Lublin University of Technology, Poland \\ habrova@tf.czu.cz, valasekp@tf.czu.cz
}

\begin{abstract}
Composite materials rank among the structural materials with a highly promising trend. The main advantage of composite materials is the synergistic effect of the individual sub-components of the system, which allows great adaptation of these materials and excellent mechanical properties. In recent years, the substitution of inorganic materials with organic materials is increasingly used in the field of composite systems. From the materials engineering point of view, this substitution makes use of very interesting properties of natural fillers. These materials are environmentally friendly and their prices are usually lower than similar synthetic fillers. However, it is also necessary to mention the negative side of organic fillers and that is their natural character. Natural fillers are so different from one another and evince greater variance than the observed values of synthetic materials. In terms of long-term applications, the degradation of natural materials can rank among limits. Natural particulate fillers can be utilized in interaction with reactive resins; they can reduce the final price while maintaining the adhesive characteristics. This paper describes the adhesive characteristics of reaction resins filled with microparticles prepared from pomace seeds of Phoenix dactylifera and it also describes the degradation of these materials. A climatic chamber was used for this experiment. Describing the degradation processes it is important to define application areas. Electron microscopy was used when evaluating the failure of bonded joints. The degradation corresponding to 35 cycles resulted in a $37 \%$ decrease in shear strength.
\end{abstract}

Keywords: composite system, mechanical properties, Phoenix dactylifera, SEM.

\section{Introduction}

Composite materials are materials that combine mechanical and physical properties of their subphases, currently, the composite systems are widely used in industries due to their flexible properties $[1 ; 2]$. Particulate fillers in polymer materials are used primarily to increase the hardness, abrasion resistance or optimize the tensile characteristics [3; 4]. The presence of particles leads to optimize the shear strength while reducing the prices of the resulting joint in the area of bonded joints. Currently, the synthetic materials are increasingly replaced with natural ones. The natural fibers and particles are used in the composite systems. The particles based on wood (e.g., wood flour, flour made from bamboo) or biomass resulting from processing of certain species of plants and their fruit (Jatropha curcas) can be used as a filler for composite systems [5; 6]. Natural particles minimize the cost and optimize certain mechanical characteristics [6-8]. The interfacial interaction is an important factor from the resulting mechanical characteristics point of view. The chemical surface treatment is often used to optimize the reinforcement on the natural basis. The adhesive and cohesive characteristics of the composite system affect the concentration of particles and their morphology - which defines, for example, the formation of a mechanical bond between the particle and the used matrix.

Degradation of polymers in terms of application and product lifecycle is a very important factor. Degradation can be characterized as an undesirable change of properties over time; this change is primarily associated with changes in molecular weight and structure of the material. [9] The factors causing degradation of polymeric materials can include temperature, humidity, and also the action of microorganisms. Adhesive bonds based on the composite, where the matrix is epoxy resin, are often exposed to various degradation effects [10-13]. The filler, which is present in order to optimize some mechanical properties (the shear strength in the case of adhesive bonds), can negatively affect the process of degradation, for example, by its absorptivity. Natural materials, which can form the filler, are very prone to degradation and thus can affect the entire process of degradation.

The aim of the experiment was to describe the degradation process - shear strength changes - of adhesive bonds formed by the composite system based on natural particles prepared from the biomass formed during the processing of fruits (dates) from Phoenix dactylifera plant and epoxy resins. Thus obtained biomass could be considered as biological waste, ecological use of which from the point of economic and environmental view is desirable. The experiment thus describes degradation of materials sensitive to the environment, the production of which is inexpensive. 


\section{Materials and Methods}

Low molecular weight epoxy resin and hardener on basis of polyamide was used in the experiment - two-component epoxy resin with density $1.15 \mathrm{~g} \cdot \mathrm{cm}^{-3}$. As a filler biomass was used resulting from the processing of fruits - dates - from the plant Phoenix dactylifera - the country of origin China. Specifically, the seeds of dates. Knife mill with a speed of $20000 \mathrm{rpm} \cdot \mathrm{min}^{-1}$ was used for preparation of particles from seeds of dates. The particles were dried at $105^{\circ} \mathrm{C}$ and subsequently sorted using analytical sieves. The particles that passed the analytical sieve with a mesh size of $100 \mu \mathrm{m}$ were used in the experiment.

Composite systems that were used for joining the steel sheets were prepared by mechanical mixing of epoxy resin and particles. Two concentrations of 5 and $10 \mathrm{wt}$. \% were used.

Filled epoxy resin was applied to a sheet of carbon steel. The surface of the steel sheets S235J0 adherent, was blasted and degreased. The surface roughness was specified on the touch roughness tester Surftest 301. The prepared lap joints were placed in the degradation chamber, which was set to degradation cycle according to Fig. 1 . Temperature $\left(70{ }^{\circ} \mathrm{C}\right.$ and $\left.-40{ }^{\circ} \mathrm{C}\right)$ and humidity $(90 \%$ and $50 \%-$ CSN EN ISO 9142) were regulated during the degradation process. The test specimens were removed from the chamber after every end of the 7 cycles $(1$ cycle -24 h). Overall, it was thus repeated $5 \times 7$ cycles $(35$ cycles $-840 \mathrm{~h})$.

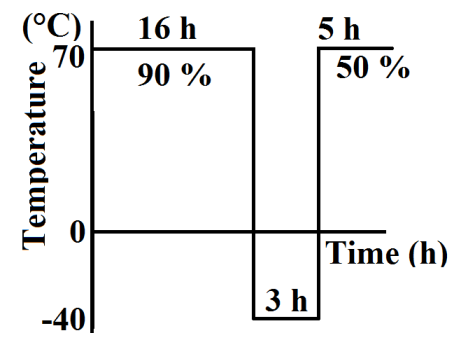

Fig. 1. Representation of the degradation cycle in the climatic chamber

The test specimens were left for $24 \mathrm{~h}$ at room temperature after removal from the climatic chamber, and then the shear strength was tested in accordance with the standard CSN EN 1465.

The type of breach of the bond was evaluated in accordance with the standard ISO 10365. Statistical analysis of the data was carried out by ANOVA and T-test with the significance level of $\alpha=0.05$. Null hypothesis $\left(H_{0}\right)$ was expressed; its validity shows the statistically insignificant difference of the observed statistical data.

Electron microscopy Tescan Mira 3 GXM equipped with an energy dispersive X-ray (Oxford XMaxN) was used for the optical analysis of the samples and the analysis of interphase interaction.

\section{Results and Discussion}

Filler particles were sorted through a sieve analysis. The specific particle sizes, which were used in the experiment, are shown in the histogram - Fig. 2. Particle surface was assessed at the same time by electron microscopy, images from electron microscope are shown in Fig. 3.

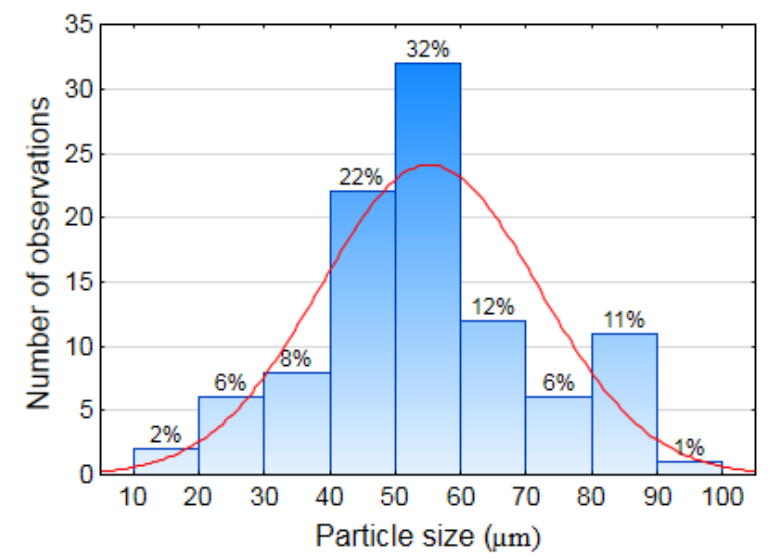

Fig. 2. Histogram of the particle size made from seeds of dates 


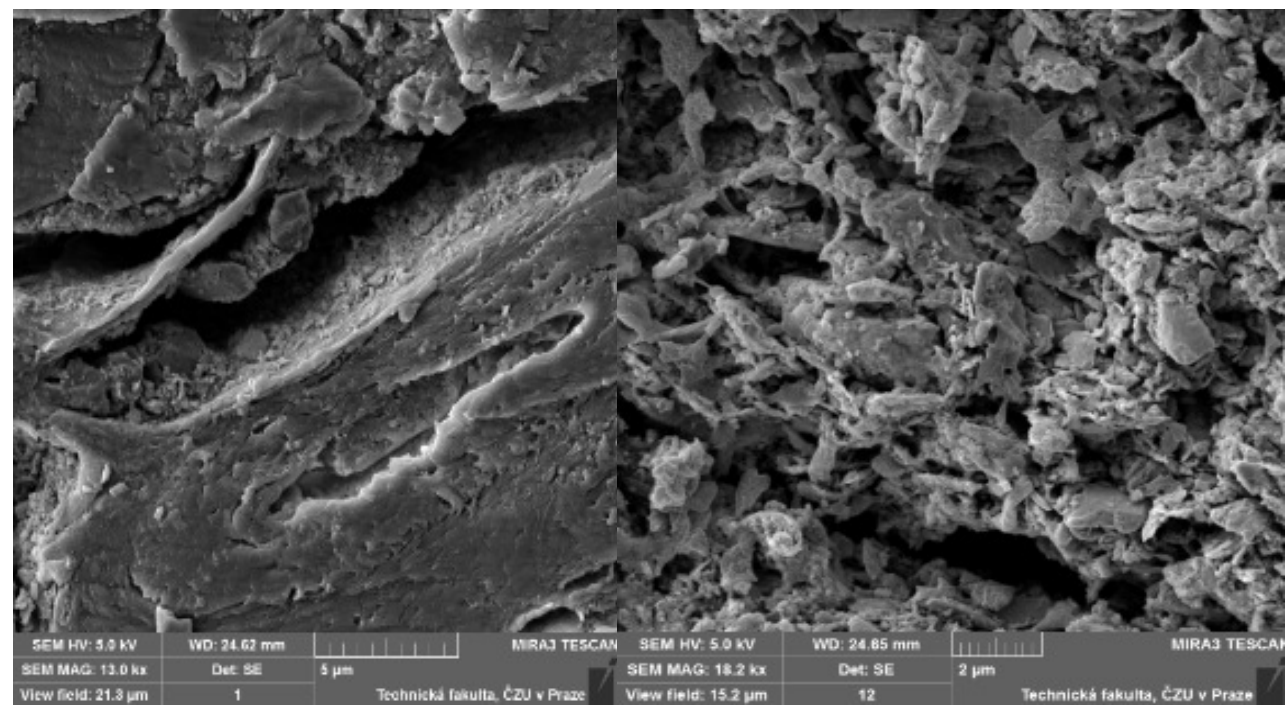

Fig. 3. Morphology of particles prepared from seeds of dates: magnitude $13.0 \mathrm{k} \mathrm{x}$ (left) and $18.2 \mathrm{k} \mathrm{x}$ (right)

The basic roughness parameters $R_{a}$ and $R_{z}$ were evaluated on the steel sheets at the place of joint prior to applying the filled epoxy resin. These parameters are summarized in the following Fig. 4.

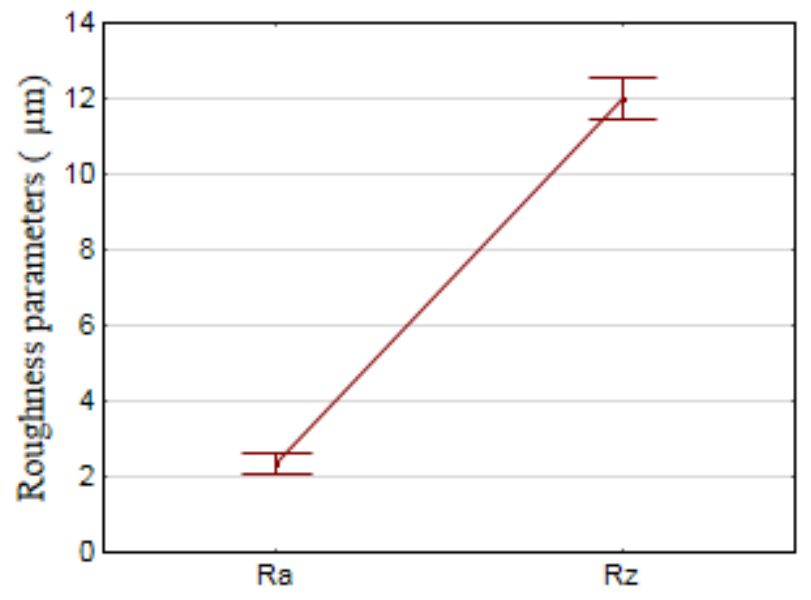

Fig. 4. Roughness parameters on the steel sheets $\boldsymbol{R}_{a}$ a $\boldsymbol{R}_{z}$

The shear strength of unfilled epoxy resin was compared with the shear strength of the filled resin (see Tab. 1). The T-test results confirmed that there is not statistically significant difference between the compared data files $(p>0.14)$.

Table 1

\section{Comparison of unfilled resin with resins filled with particles made from seeds of dates}

\begin{tabular}{|c|c|c|}
\hline$H_{0}:(\mathrm{p}>0.05)$ & $5 \%$ & $10 \%$ \\
\hline F-test: Unfilled resin (p) & 0.76 & 0.14 \\
\hline T-test: Unfilled resin (p) & 0.71 & 0.64 \\
\hline
\end{tabular}

The results of the dependence of the degradation time (1 week -7 cycles) are shown in Fig. 5 (left), the test samples before and after degradation are shown in Fig. 5 - right. The curve of degradation of joints formed by filled epoxy resin is supplemented with the curve that describes the degradation of unfilled resins. This representation allows defining the influence of the used filler on the actual degradation. The typical character of the bonded failure showed signs of adhesive failure. This type of failure did not change due to degradation. 

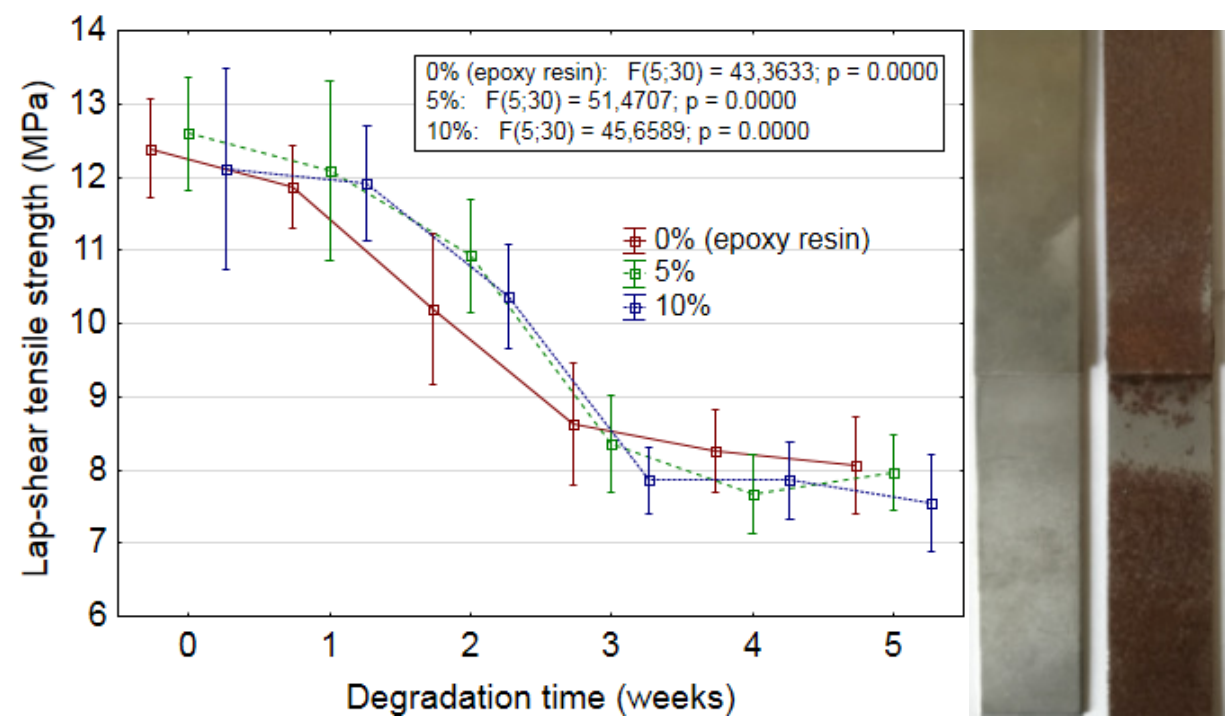

Fig. 5. Dependence of the shear strength of adhesive bonds on the length of degradation (left), test samples before and after degradation (right)

Electron microscopy was used to assess both interaction between the adherent and filled epoxy resin and the actual interfacial interaction. Fig. 6 shows a section in the bond, where a good interaction between the steel surface and the applied filled system is evident.

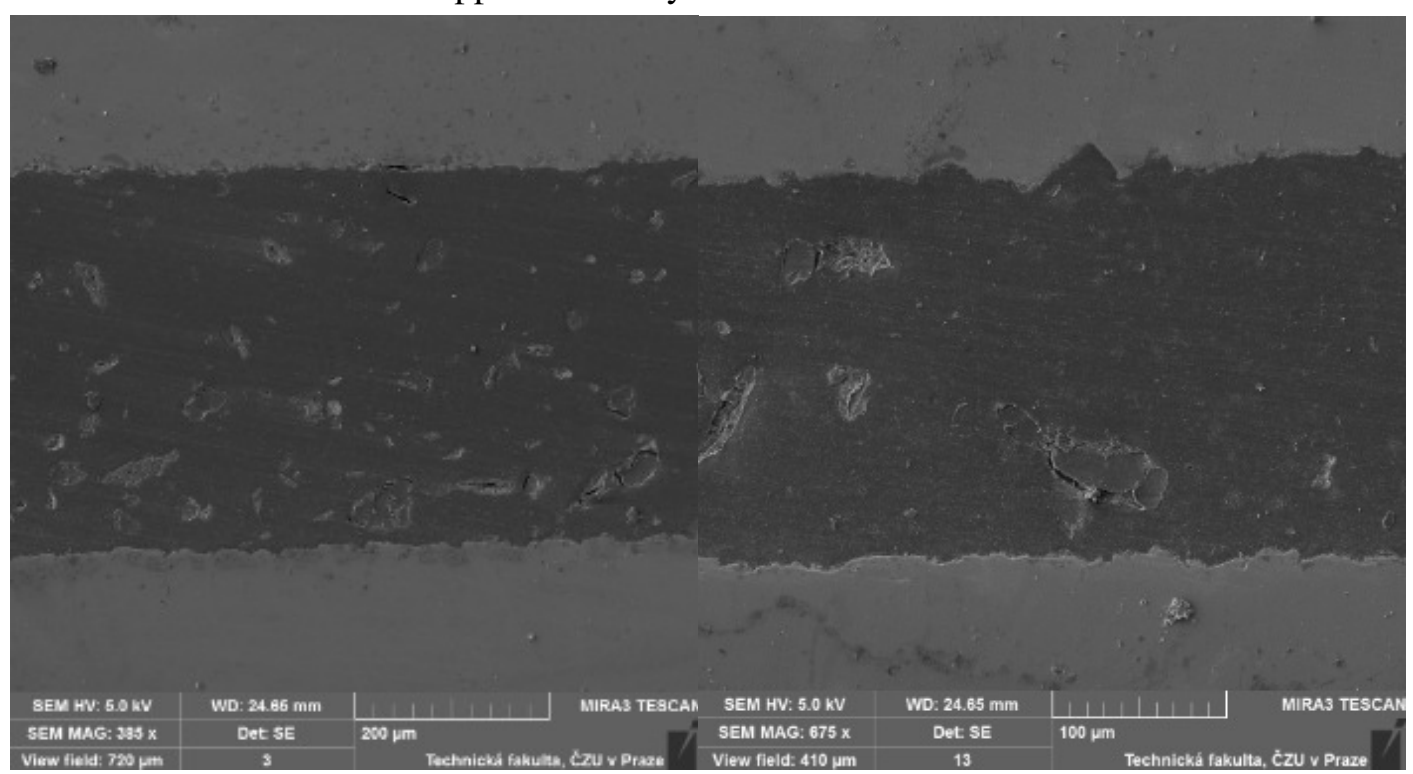

Fig. 6. Section through the bond (adhesive joint): magnitude $383 \times$ (left) and $675 \mathrm{x}$ (right)

Some filler particles were not optimally wetted by the epoxy resin according to the picture of the bond section. The details of the interaction were taken to assess the interfacial interactions. As apparent from Fig. 7, there was not a perfect wetting for some particles. This was caused by the fact that there was no any chemical or other treatment of the particles prior to application of them into the resin. The modification of particles was not applied because of minimizing the environmental and financial burdens.

The experiment confirmed the conclusions of a number of authors [5-7] that the inclusion of organic as well as inorganic particles can be used to reduce the cost of adhesives without decreasing the values of shear strength. The presence of fillers did not significantly reduce the value of shear strength of the resin. Analysis of interphase interaction revealed that epoxy resin does not optimally wet the biological particles. Degradation caused after the reference interval of $840 \mathrm{~h}$ (35 days) decreases the tensile strength of epoxy resin from $12.39 \pm 0.58 \mathrm{MPa}$ to $8.06 \pm 0.57 \mathrm{MPa}$ (decrease 
$5 \%$ ), composite $5 \%$ from $12.60 \pm 0.68 \mathrm{MPa}$ to $7.89 \pm 0.46 \mathrm{MPa}$, composite $10 \%$ from $12.11 \pm$ $1.20 \mathrm{MPa}$ to $7.55 \pm 0.57 \mathrm{MPa}$.
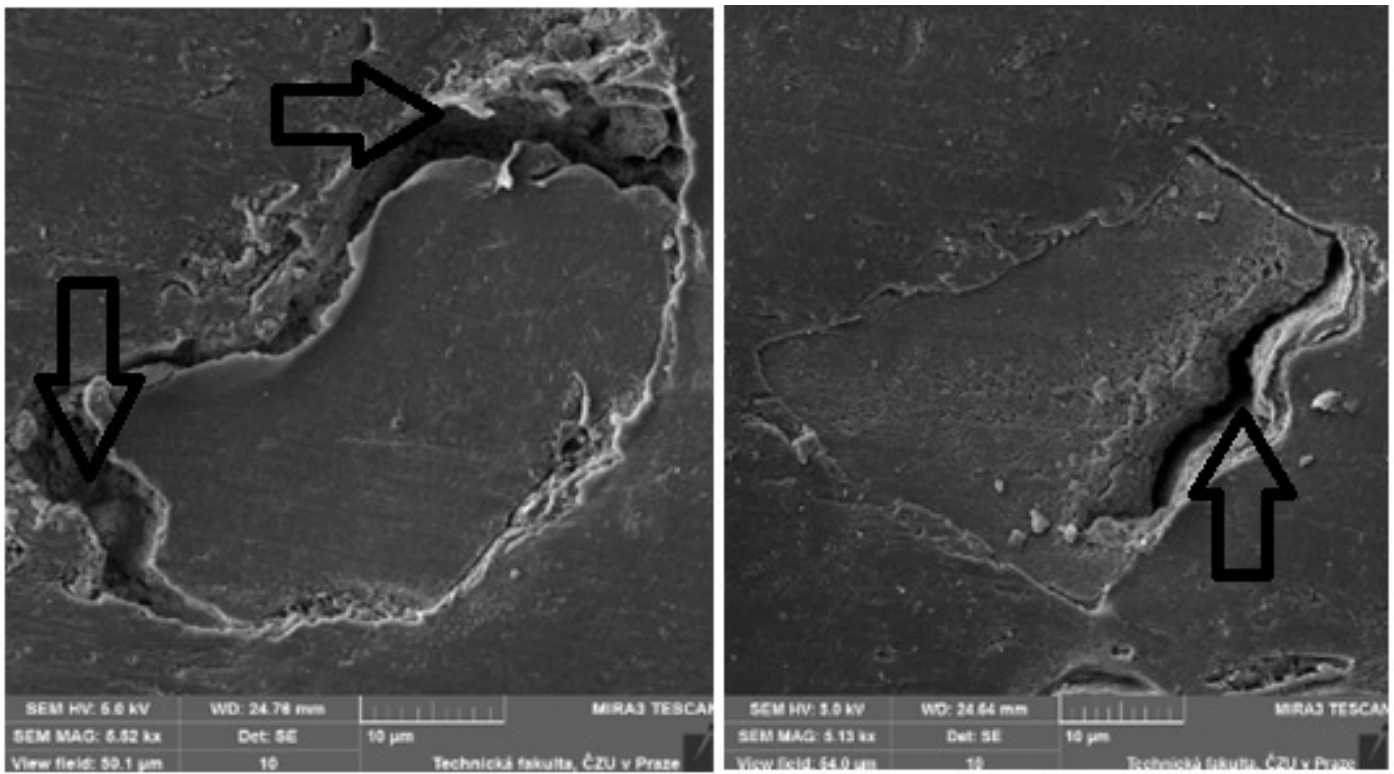

Fig. 7. Detail of interfacial interaction

\section{Conclusions}

Description of degradation of composite systems is important from the perspective of the life cycle of products made from these materials. Shear strength is one of the important factors that determine the possibilities of application of composites in the form of filled thermosetting resins, which are used for adhesive bonding. The description of the decrease in shear strength due to the degradation is crucial, and the results of the experiment can be summarized as follows:

1. The presence of particles prepared from the seeds of dates with the size less than $100 \mu \mathrm{m}$ did not significantly change the shear strength of the joints between the steel sheets.

2. The used filler did not significantly affect the rate of degradation comparing to the unfilled resins - degradation was evaluated via tensile strength.

3. Shear strength decreased by a maximum of $37 \%$, during the degradation process.

\section{Acknowledgement}

This paper has been made with the assistance of the grant CULS - IGA TF 2017:31140/1312/3113.

\section{References}

1. Affatato S., Ruggiero A., Merola, M. Advanced biomaterials in hip joint arthroplasty. A review on polymer and ceramics composites as alternative bearings. Composites Part B: Engineering, 83, 2015, pp. 276-283.

2. Taddei P, Ruggiero A., Pavoni E., Affatato, S. Transfer of metallic debris after in vitro ceramicon-metal simulation: Wear and degradation in Biolox® Delta composite femoral heads. Composites Part B: Engineering, 2016, in-press

3. Dědičová K., Valášek, P. Influence of glass powder size sorting on properties of composite systems. Scientia Agriculturae Bohemica, 47, 2016, pp. 25-31.

4. Müller M., Valášek P., Rudawska, A. Mechanical properties of adhesive bonds reinforced with biological fabric. Journal of Adhesion Science and Technology, 9, 2017, pp. 1-13.

5. Renner K., Kenyó C., et al. Micromechanical deformation processes in PP/wood composites: Particle characteristics, adhesion, mechanisms. Composites Part A: Applied Science and Manufacturing, 41(11), 2010, pp. 1653-1661. 
6. Shivamurthy B., Murthy K., et al. Mechanical properties and sliding wear behavior of Jatropha seed cake waste/epoxy composites. Journal of Material Cycles and Waste Management, 2014, pp. 1-13.

7. Ruggiero, A., Valášek, P., Müller, M. Exploitation of waste date seeds of Phoenix dactylifera in form of polymeric particle biocomposite: Investigation on adhesion, cohesion and wear. Composites Part B: Engineering, 104, 2016, pp. 9-16.

8. Dwivedi, U.K., Chand, N. Influence of wood flour loading on tribological behavior of epoxy composites. Polymer Composites, 29(11), 2008, pp. 1189-1192.

9. Grassie N., Guy M.I., Tennent, N.H. Degradation of epoxy polymers: Part 1-Products of thermal degradation of bisphenol-A diglycidyl ether. Polymer Degradation and Stability, 12, 1985, pp. 65-91.

10. Soykok I.F. Degradation of single lap adhesively bonded composite joints due to hot water ageing. Journal of Adhesion, Vol. 93, 2017, pp. 357-374.

11. Chocholouš P., Müller, M. Mechanical surface treatment for adhesive bonding technology in sandwich production. In 5th International Conference on Trends in Agricultural Engineering 2013, Prague: Czech University of Life Sciences Prague, 2013. pp. 249-253

12. Müller, M. Influence of Specific Degradation Liquid Contaminants of Agricultural Production on Shear Impact Strength of Adhesive Bond. In 6th International Scientific Conference on Rural Development - Innovations and Sustainability 28.11.2013, Kaunas, Akademija, LITHUANIA. Akademija, Lithuania, 2013. pp. 89-94.

13. Cidlina, J., Müller, M. Influence of overlapping length on peeling strength of adhesive bonds. In 14th International Scientific Conference on Engineering for Rural Development 2015, Latvia University of Agriculture, 2015. pp. 761-765. 